Reprinted with permission from: Canadian Journal of Botany 77:1684-1688 (1999).

Published and copyrighted by: National Research Council of Canada, http://www.nrc.ca/cisti/journals/.

\title{
Reproductive biology of leafy spurge (Euphorbia esula L.): Breeding system analysis $^{1}$
}

\author{
SARENA M. SELBO and JEFFREY S. CARMICHAEL* \\ Department of Biology, University of North Dakota Grand Forks, ND 58202, Phone: (701) 777-4666, Fax: (701) 777- \\ 2623, *Author for correspondence e-mail: carmicha@plains.nodak.edu
}

\begin{abstract}
:
Leafy spurge (Euphorbia esula L.) represents a non-native, invasive weed that dominates many regions across North America. While many research efforts are aimed at controlling the growth and spread of this plant, relatively little is known about its breeding system. This study provides evidence that leafy spurge is self-compatible, with selfed plants producing roughly half as many seeds as outcrossed plants. Unpollinated flowers failed to set seed and thus preliminary tests for apomixis were negative. However, microscopic examination of pollinated flowers revealed that pollen tubes did not appear to enter ovules in either selfed or outcrossed flowers. Therefore, leafy spurge exhibits structural evidence that suggests pseudogamy may play a role in the reproductive strategies of this invasive weed.
\end{abstract}

\section{Keywords:}

Leafy spurge, Euphorbiaceae, Euphorbia, apomixis, breeding system, selfcompatibility.

\section{Introduction}

Leafy spurge (Euphorbia esula L.) is a herbaceous perennial that has flourished as a weed of economic and ecological importance. This plant was introduced to North America from continental Europe and Asia in the early nineteenth century as a contaminant in

\footnotetext{
${ }^{1}$ Submitted to Canadian Journal of Botany, December 22, 1998
} 
seed grain (Messersmith 1983). Since that time, it has become widespread and now infests over 5 million acres in North America (Brinkman et al. 1997). Most of the current research on this invasive plant is concentrated on its eradication and emphasizes various chemical, biological, and mechanical control agents (Carlson and Littlefield 1983; Lym and Messersmith 1983; Lym et al. 1996).

It is plausible that the success of biological control methods might be tightly associated with basic aspects of the reproductive biology of leafy spurge. However, virtually no comprehensive reproductive information on this plant has been available, except for studies on clonal propagation (Raju et al. 1963), flower structure (Hanson and Rudd 1933) and ovule development (Carmichael and Selbo 1999). In fact, a report by Selleck et al. (1962) represents the only published account of breeding strategies of leafy spurge. Unfortunately, that study did not examine whether apomictic seed development was evident nor did it indicate whether any measure was taken to prevent the potential crossing of genetically identical plants (ramets) that may occur within clonal patches.

Given this lack of reproductive information, an analysis of the breeding system of leafy spurge is merited. This study examines the reproductive biology of leafy spurge and is meant to supplement a recent account of ovule, embryo, and endosperm development (Carmichael and Selbo 1999). This study examines self-compatibility and provides structural evidence that leafy spurge may exhibit pseudogamous apomixis (i.e., pollination triggers embryo and seed development without fertilization actually taking place).

\section{Materials and methods}

\section{Breeding system analysis}

Leafy spurge plants were sampled during the summer of 1998 from Oakville Prairie, a native prairie land located 13 miles west of Grand Forks, ND, U.S.A. Treatments were carried out to test for self-compatibility and apomixis. Controlled pollinations were maintained by bagging flowers with nylon mesh before anthesis. Plants were checked daily with hand-pollinations performed roughly a week after bagging. Each flower was pollinated a single time with excess pollen.

Apomixis was tested for by emasculating 112 flowers on 20 separate plants prior to anthesis. Those same flowers were then rebagged and monitored over the course of four weeks. Self-compatibility was assayed by pollinating 90 previously bagged flowers on 20 separate plants with pollen from other flowers on the same plant. Finally, 122 flowers on 20 separate plants were outcrossed and bagged in a similar manner. Pollen from a distant patch of at least $25 \mathrm{~m}$ away was used to reduce the likelihood of using pollen from genetically identical ramets in the outcross experiments. All flowers were monitored daily over a six-week period and observed for evidence of fruit and seed set. Toward the end of the six-week period, flowers were collected and dissected to verify whether mature seeds were present in enlarged ovaries. 


\section{Fluorescence microscopy of pollen tubes}

Flowers from outcrossed and selfed plants were collected 12, 24, 48 and 72 hours after pollination and prepared for callose - aniline blue fluorescence according to a modified method of Currier (1957). Plant material was fixed in formalin-alcohol-acetic acid (FAA) for 24 hours at $4^{\circ} \mathrm{C}$, washed thoroughly with distilled water, and soaked in $4 \mathrm{M}$ $\mathrm{NaOH}$ overnight. Specimens were again washed with distilled water and stained with decolorized aniline blue. The preparations were observed and photographed on an Olympus BX 60 microscope equipped with UV epifluorescence (HBO $100 \mathrm{~W}$ burner, Olympus wide band UV filter cube).

\section{Brightfield microscopy}

Ovaries collected for observation were trimmed and fixed in 4\% acrolein dissolved in 0.05 M TRIZMA buffer, ( $\mathrm{pH} 7.2$ ), for 24 hours at room temperature. The chemically fixed specimens were rinsed two times in TRIZMA buffer, dehydrated through an ethanol series $(10 \%, 20 \%, 30 \%, 50 \%, 75 \%, 95 \%, 100 \%, 30$ minutes per step), and infiltrated over a seven-day period with glycol methacrylate (JB-4 Embedding Kit, Polysciences, Inc.). Ovules were then embedded and the embedding medium was polymerized in an oxygen-free environment by flushing nitrogen gas through a closed chamber. Embedded samples were serially sectioned on a RMC 920 MT rotary microtome into ribbons of serial sections at thicknesses of 3-5 $\mu \mathrm{m}$ with a glass knife. Ribbons were mounted on microscope slides, stained with toluidine blue (O'Brien and McCulley 1981), and preserved with mounting medium.

\section{Results}

Of the 112 flowers that were emasculated and tested for apomictic seed development, none produced seed (Table 1). Ovaries of these unpollinated flowers were aborted within seven days after emergence of the stigma from surrounding bracts. Of the 122 outcrossed flowers, $63 \%$ produced seeds, while only $29 \%$ of the 90 selfed flowers produced seeds (Table 1). The vast majority of those flowers that set seed formed three seeds per flower (one seed per locule). A few flowers in both the self and outcross experiments did produce less than three seeds per flower, but these instances were rare. Flowers that failed to set seed showed no signs of ovule enlargement or maturation. Thus, their failure to produce seed was likely a result of total flower abortion and not individual embryo abortion.

Table 1. Breeding system analysis of leafy spurge (Euphorbia esula).

\begin{tabular}{lcc}
\hline Treatment & No. of Flowers Treated & $\begin{array}{c}\text { No. of Flowers } \\
\text { Producing Seed }\end{array}$ \\
\hline Emasculated & 112 & 0 \\
Selfed & 90 & 26 \\
Outcrossed & 122 & 77 \\
\hline
\end{tabular}

Page 3 of 8 


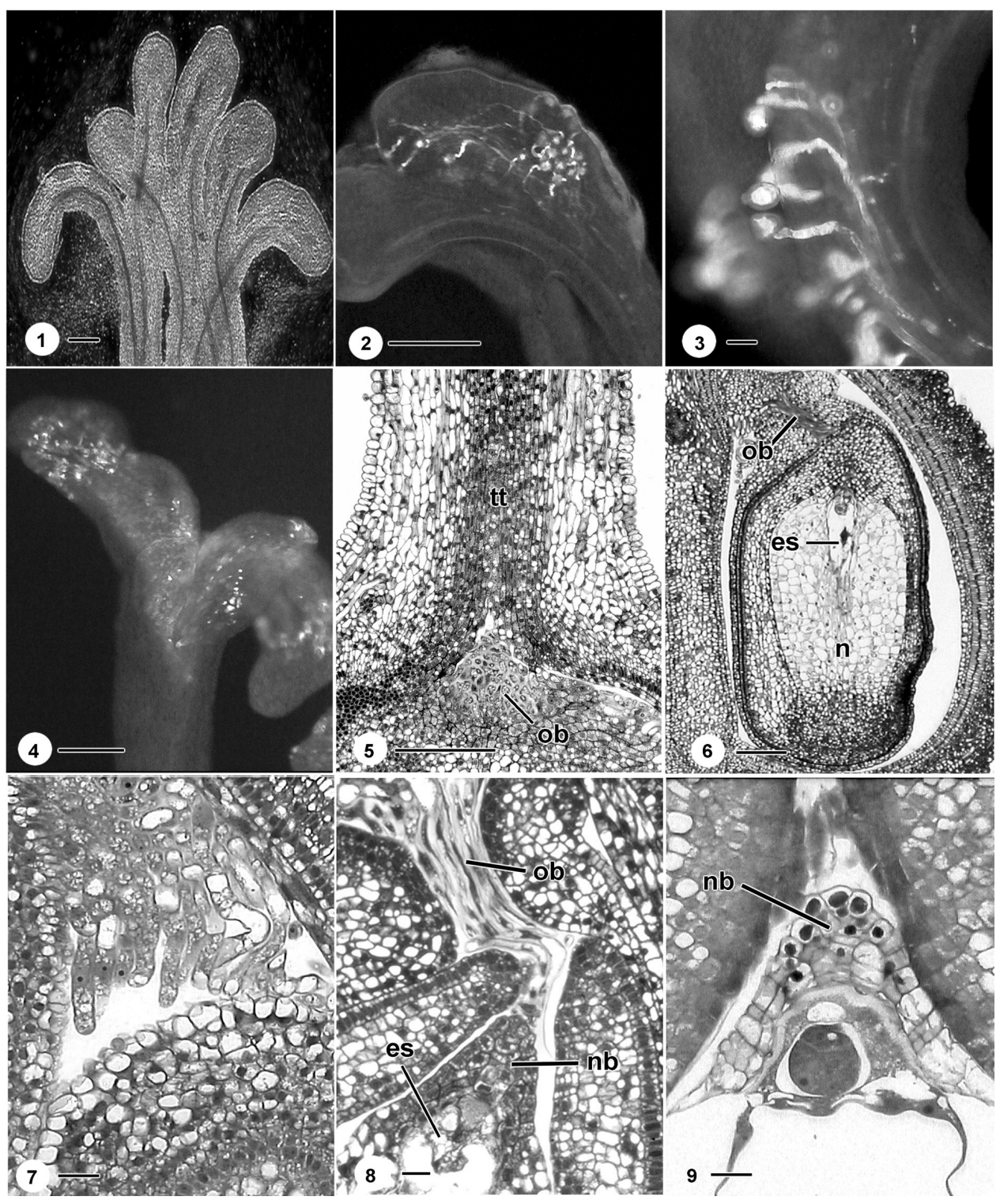

Figs. 1-9. Reproductive structures of leafy spurge (Euphorbia esula). Fig. 1. Low magnification image of the bifurcated stigmatic branches viewed under fluorescence and phase contrast microscopy. Bar $=200 \mu \mathrm{m}$. Fig. 2. Germination of numerous pollen grains on one branch of a stigma. Bar $=300 \mu \mathrm{m}$. Fig. 3. High magnification image of pollen tube growth into the stigma. Note the presence of several elongated pollen tubes. Bar $=30 \mu \mathrm{m}$. Fig. 4 . Self-pollinated stigma showing the presence of callose deposits (bright areas on stigmatic surface). Deposits were not observed in outcrossed flowers. Bar $=300 \mu \mathrm{m}$. Fig. 5. Longitudinal section of the lower $2 / 3$ of a style. No pollen tubes were observed in this region. The obturator originates as a distinct mass of cells at the base of the stylar region. Bar $=100 \mu \mathrm{m}$. Fig. 6. Longitudinal section of a single ovule showing obturator tissue at the micropylar end. Bar $=100 \mu \mathrm{m}$. Fig. 7. High magnification image of elongate obturator cells which completely fill the micropylar region. Bar $=20 \mu \mathrm{m}$. Fig. 8. Longitudinal section of an ovule with the nucellar beak extending near the micropyle. Bar $=20 \mu \mathrm{m}$. Fig. 9. Longitudinal section of a developing embryo. Bar $=20 \mu \mathrm{m}$. e, embryo; es, embryo sac; $\mathbf{n}$, nucellus; nb, nucellar beak; ob, obturator; tt, transmitting tissue. 
Fluorescence microscopy was used to observe 12, 24, 48 and 72-hour post-pollination stigmas and assess the presence or absence of pollen germination and pollen tube growth. The stigmatic surface of leafy spurge is composed of three bifurcated branches, each of which is connected to a single carpel (Fig. 1). Numerous pollen grains germinate (Fig. 2) and grow into the stigmatic tissue of selfed and outcrossed flowers (Fig. 3). Pollen tubes were observed within the style, but were never seen to enter the ovule. In fact, regardless of the time elapsed after pollination, pollen tubes were never observed past the uppermost one-third of the style. The flowers collected 72 hours after pollination contained embryos and endosperm, but pollen tubes were not observed in or near the ovules. The apparent lack of fertilization was evident in both the selfed and outcrossed flowers.

An interesting phenomenon was observed on the stigmatic surface of the selfed flowers. A deposit, presumably callose (based on its fluorescence pattern), was acquired on the stigmas after self-pollination (Fig. 4). These callose deposits appeared as brightlyfluorescent regions scattered across the surface of the stigma. Despite these deposits, pollen tubes were initiated on the stigmas of most of the selfed flowers. Callose was not observed on any of the outcrossed flowers.

Brightfield microscopy of sectioned ovules revealed the presence of an obturator (Figs. 5-8) and a nucellar beak (Fig. 8). The obturator tissue originates as a distinct region of densely cytoplasmic cells located near the base of the style where the three stigmatic branches converge (Fig. 5). The transmitting tissue is solid, lacks a distinct passageway for pollen tube growth, and terminates just distal to where the obturator originates (Fig. 5). The obturator is fairly extensive and forms as an outgrowth of the placental tissue. It consists of distinct glandular cells (Fig. 7) which grow toward the ovule and ultimately deep into the micropyle where they are found positioned near the nucellar beak (Fig. 8). As with the preparations for fluorescence microscopy, not a single sectioned ovule revealed the presence of pollen tubes anywhere near the nucellus or embryo sac. The nucellar beak region was also never observed to contain pollen tubes (or remnants of them) or any type of canal that would facilitate growth of pollen tubes into the embryo sac (Figs. $8,9)$. Although pollen tubes did not appear to enter ovules, embryos were consistently observed in enlarged ovules (Fig. 9).

\section{Discussion}

The documentation of self-compatibility in leafy spurge was not surprising as this phenomenon is common in many flowering plants, including other members of the Euphorbiaceae (East 1940; Kao and McCubbin 1996). Self-compatibility has long been suggested to be favorable when a plant colonizes a new area. Since invasive species begin as small populations, they typically spread quickly to become established as a dominant species (Daehler 1998). As an invasive plant, self-compatibility may, in part, be responsible for the rapid and widespread infestations of leafy spurge across North America.

Page 5 of 8 
Although leafy spurge is self-compatible, our results show that fruit set in selfed flowers is approximately one-half of that in outcrossed. Similar results were documented previously by Selleck et al. (1962) who reported that $28 \%$ of leafy spurge flowers produced seed when pollinated by males on the same cyathium while $56.4 \%$ of outcrossed flowers produced seeds. Rates of seed set in our outcrossed flowers may be higher than those reported by Selleck et al. (1962) since we used distant plants for pollinating and thus reduced the likelihood of using pollen from genetically identical ramets.

The mechanism for the decreased seed set in selfed plants is unclear, but it is interesting to note that only the selfed plants produced a callose deposit on the stigma after pollination. Callose can develop for a variety of reasons such as an intermediate in the degeneration of cell walls and in response to wounding (Currier 1957). Callose may also form as a rejection phenomenon during incompatible matings (Dumas and Knox 1983). In leafy spurge, the callose found on the stigmatic surface may hinder the growth of pollen tubes into the inner stigmatic tissues and thus play a role in the reduced rates of seed production in selfed versus outcrossed flowers.

Although pollination is a prerequisite for fruit and seed set, we were unable to track pollen tubes into ovules. Pollen tubes were not observed in the basal region of any of the sectioned styles nor in any styles prepared for pollen tube fluorescence. No pollen tubes or any type of canal was observed in the nucellar beak, even in those ovules that clearly had embryos. The lack of a distinct passageway through the transmitting tissue of leafy spurge may potentially hinder growth of pollen tubes to the ovule. A similar phenomenon was observed in the pseudogamous apomict, Commiphora wighii Arnott (Gupta et al. 1998). In this plant, cells of the transmitting tissue are arranged in a relatively scattered fashion and, therefore, do not provide a conduit for pollen tube growth.

Given the conditions stated above, it is plausible that leafy spurge is a pseudogamous apomict and that pollen is needed to trigger apomictic development of embryos and seeds. Apomictic species are frequently aggressive weeds (Stebbins 1974) and this phenomenon is consistent with the life history of leafy spurge as an invasive, dominating weed. Indeed, apomixis itself is common among flowering plants and has been demonstrated in over 40 families (Gupta et al. 1996; Calzada et al. 1996). Among the Euphorbiaceae, five genera have been reported as containing species that display apomixis. In fact, Euphorbia dulcis is considered a pseudogamous apomict as this plant shows no pollen tube growth in the stylar tissue, ovule or embryo sac, yet requires pollen for seed set (Kapil 1961).

The relationship between apomictic seed development and reduced fruit and seed set in selfed versus outcrossed flowers is intriguing. Even though self and outcross pollen does not appear to contribute genetic information to embryos, outcrossed flowers clearly show higher rates of fruit and seed set than selfed flowers. Although differential fruit set in selfed versus outcrossed flowers was initially unexpected, these results are consistent with the results of Noirot et al. (1997) who showed that self-compatibility in apomicts is necessary for the maintenance of apomictic populations.

Although our results provide structural evidence of pseudogamy, tests using molecular approaches may prove useful in future verification of this phenomenon. For example, the Random Amplified Polymorphic DNA (RAPD) technique has been used to ascertain 
genetic variation that may indicate asexual modes of reproduction in plants (Holm and Ghatnekar 1996; UrRahman et al. 1997; Nassar et al. 1998a; Nassar et al. 1998b). RAPDs and other molecular techniques might also be used to increase our understanding of the population structure and clonal nature of large patches of leafy spurge (Rowe et al. 1997). It is hoped that further understanding of reproductive strategies will aid in the control of leafy spurge and other invasive weeds.

\section{Acknowledgments}

The authors thank the following people for valuable discussions throughout this project: J. LaDuke, C. Haycraft, C. Hughes, A. Gerber, and J.P. Wenger. Support for this work was provided by a grant-in-aid of research by North Dakota Experimental Program to Stimulate Competitive Research (EPSCoR) to J.S.C. and a Howard Hughes Undergraduate Research Fellowship from the University of North Dakota and a North Dakota EPSCoR AURA (Advanced Undergraduate Research Assistantship) to S.M.S.

\section{References}

Brinkman, M.A, Clay, S.A., and Jackson, J.J. 1997. Improving establishment of flea beetles on leafy spurge. Midwest Biol. Contr. News 4(11).

Calzada, J.V., Crane, C.F., and Stelly, D.M. 1996. Apomixis: the asexual revolution. Science Washington, D.C. 247: 1322-1323.

Carlson, R. B., and Littlefield, L. J. 1983. The potential for biological control of leafy spurge in North Dakota. N. D. Farm Res. 40(5): 14-15.

Carmichael, J.S., and Selbo, S.M. 1999. Ovule, embryo sac, embryo, and endosperm development in leafy spurge (Euphorbia esula L.). Can. J. Bot. 77:599-610.

Currier, H.B. 1957. Callose substance in plant cells. Am. J. Bot. 44: 478-488.

Daehler, C.C. 1998. Variation in self-fertility and the reproductive advantage of self fertility for an invading plant (Spartina alterniflora). Evol. Ecol. 12: 553-568.

Dumas, C., and Knox, R.B. 1983. Callose and determination of pistil viability and incompatibility. Theor. Appl. Genet. 67:1-10.

East, E.M. 1940. The distribution of self-sterility in the flowering plants. Proc. of the Am. Philos. Soc. 82: 449-518.

Gupta, P., Shivanna, K.R., and Mohan Ram, H.Y. 1996. Apomixis and polyembryony in the guggul plant, Commiphora wighii. Ann. of Bot. 78: 67-72.

Gupta, P., Shivanna, K.R., and Mohan Ram, H.Y. 1998. Pollen-pistil interaction in a non-pseudogamous apomict, Commiphora wighii. Ann. of Bot. 81: 589-594.

Hanson, H.C., and Rudd, V.E. 1933. Leafy spurge - Its life history and habits. N. D. Agric. Exp. Stn. Bull. 266.

Holm, S., and Ghatnekar, L. 1996. Apomixis and sexuality in hexaploid Potentilla argentea. Hereditas 125: 53-60.

Kao, T.-H., and McCubbin, A.G. 1996. How flowering plants discriminate between self and non-self pollen to prevent inbreeding. Proc. Natl. Acad. Sci. USA 93: 12059-12065. 
Kapil, R.N. 1961. Some embryological aspects of Euphorbia dulcis L. Phytomorphology 11: 24-36.

Lym, R.G. and Messersmith, C.G. 1983. Control of leafy spurge with herbicides. N. D. Farm Res. 40(5): 16-19.

Lym, R., Nissen, S., Rowe, M., Lee, D., and Masters, R. 1996. Leafy spurge (Euphorbia esula) genotype affects gall midge (Spurgia esulae) establishment. Weed Sci. 44: 629-633.

Messersmith, C.G. 1983. The leafy spurge plant. N. D. Farm Res. 40(5): 3-6.

Nassar, N.M.A., Vieira, M.A., Vieira, C., and Grattapaglia, D. 1998a. A molecular and embryonic study of apomixis in cassava (Manihot esculenta Crantz). Euphytica 102: 9-13.

Nassar, N.M.A., Vieira, M.A., Vieira, C., and Grattapaglia, D. 1998b. Molecular and embryonic evidence of apomixis in cassava interspecific hybrids (Manihot spp.). Can. J. Plant Sci. 78:349-352.

Noirot, M., Couvet, D., and Hamon, S. 1997. Main role of self-pollination rate on reproductive allocations in pseudogamous apomicts. Theor. Appl. Genet. 95:479-483.

O’Brien, T.P., and McCully, M.E. 1981. The Study of Plant Structure: Principles and Selected Methods. Termarcarphi. Wantirna, Australia:

Raju, M.V.S., Steeves, T.A. and Coupland, R.T. 1963. Developmental studies on Euphorbia esula L. Morphology of the root system. Can. J. Bot. 41: 579-589.

Rowe, M.L., Lee, D.J., Nissen, S.J., Bowditch, B.M., and Masters, R.A. 1997. Genetic variation in North American leafy spurge (Euphorbia esula) determined by DNA markers. Weed Sci. 45: 46-454.

Selleck, G.W., Coupland, R.T., and Frankton, C. 1962. Leafy Spurge in Saskatchewan. Ecol. Mono. 32: 129.

Stebbins, G.L. 1974. Flowering plants: evolution above the species level. Harvard University Press, Cambridge, Mass.

UrRahman, H., James, D.J., Hadonou, A.M., and Caligari, P.D.S. 1997. The use of RAPD for verifying the apomictic status of seedlings of Malus species. Theor. Appl. Genet. 95: 1080-1083. 